\title{
RZECZ O HISTORII NATURALNEJ, ZWIERZĘCYCH SKÓRACH I SZTUCE - RECENZJA SPEKULATYWNEJ TAKSYDERMII (SPECULATIVE TAXIDERMY) GIOVANNIEGO ALOIEGO
}

A thing about natural history, animal skins and art - a review of Giovanni Aloi's Speculative Taxidermy

\begin{abstract}
The purpose of this review is to familiarize the Polish reader with the extensive and interesting monography: Speculative Taxidermy: Natural History, Animal Surfaces, and Art in the Anthropocene, published by Columbia University Press. The Author Giovanni Aloi - art historian and museumologist, takes up the challenge of opening new fields, and asking new questions in research on taxidermy in art and science. The speculative methodological approach proposed by the author, draws on the new materialism, archology of knowledge and "speculative turn," and enables him not only to thoroughly analyze the art involving taxidermic objects, but also to conduct erudite analyzes of discourses, practices and "nexuses" defining complex human-animal relationships. Taxidermy is a pretext to reflect on the sources of animal representation in contemporary culture and discourse of natural history, as well as to show the abovementioned relationships in the context of ecological, economic and environmental crises, and the uncertainties characterizing the "dark ecology" of the Anthropocene. This work is an extremely valuable contribution to Ecocritical studies and the still developing field of animal studies.
\end{abstract}

Keywords: taxidermy, speculative, art, ecocriticism, Giovanni Aloi, animals, animal studies 
W drugiej połowie XX wieku taksydermia nie cieszyła się pochlebną opinią, szczególnie wśród badaczy i aktywistów ekologicznych. Biorąc pod uwagę rosnącą świadomość negatywnego wpływu ludzkiej działalności na systemy planetarne i dramatycznie malejącą bioróżnorodność, nietrudno dostrzec, dlaczego obiekty taksydermiczne stały się kontrowersyjne. Ze względu na kwestie etyczne i poprawność polityczną sprawa ta zaczęła budzić coraz więcej wątpliwości. Skutkiem tej sytuacji bywały nawet zorganizowane akcje pozbywania się zbiorów taksydermicznych przez niektóre instytucje muzealne. Niemniej sprawa nie była i nie jest jednoznaczna. $Z$ jednej strony (szczególnie w kontekście muzeów) taksydermia nadal przyciąga wielu zainteresowanych jej unikatowością i egzotyką. Z drugiej - zwrot ku rzeczom i dyskurs nowej materialności wpłynęły na rozwój zainteresowania unikatowym i złożonym statusem ontologicznym oraz epistemologicznym taksydermii. Charakterystyczną cechą teoretycznych podejść do taksydermii było umieszczanie jej w kontekście studiów postkolonialnych, w którym ujmowana była jako jeden z emblematycznych elementów trudnej, politycznej i kulturalnej, spuścizny imperializmu. Badacze, tacy jak Rachel Poliquin, Pauline Wakeham, Mark Simpson czy John MacKenzie ${ }^{1}$, na różne sposoby

R. Poliquin, The Breathless Zoo: Taxidermy and the Cultures of Longing, Pennsylvania State University Press, University Park 2012; P. Wakeham, Taxidermic Signs: Reconstructing Aboriginality, University of Minnesota Press, Minneapolis 2008; M. Simpson, Immaculate Trophies, „Essays on Canadian Writing” 1999, No. 68: Materializing Canada; J.M. ujawniali w swoich pracach powiązania między pojęciami klasy, rasy, płci i nauki, które były motorami wielkich polowań i wypraw przyrodniczych w poszukiwaniu idealnych okazów i trofeów w XIX i w pierwszej połowie XX wieku. Donna Haraway pisze o taksydermii jako: „sedymentacji patriarchalnych dyskursów o imperialistycznym podboju i zniewoleniu"2.

Pewne wyczerpanie tej formuły badawczej doprowadziło do częstego dziś otwartego odrzucania taksydermii w kręgach historii sztuki i ekokrytyki. Zwierzęce skóry traktowane sąjako oczywiste i już przebadane przejawy podporządkowania, uprzedmiotowienia i ludzkiego panowania nad natura. W ambitnej monografii Speculative Taxidermy: Animal Skins in the Age of Anthropocene (2018), wydanej nakładem Columbia University Press $^{3}$, włosko-amerykański historyk sztuki Giovanni Aloi wychodzi niejako naprzeciw tego rodzaju uproszczeniom i zadaje szereg istotnych pytań o reprezentacje zwierząt w sztuce oraz - szerzej - o zakres i naturę skomplikowanych relacji ludzko-zwierzęcych. Nie skupia się jednak wyłącznie ani nawet głównie na eksponatach muzealnych i obiektach kolekcjonerskich. Poszerza swoje

MacKenzie, The Empire of Nature: Hunting, Conservation, and British Imperialism, Manchester University Press, Manchester 1988.

2 D. Haraway, Teddy Bear Patriarchy: Taxidermy in the Garden of Eden, ,Social Text” 19841985, No. 11, s. 20-64. Cytaty z dzieł obcojęzycznych w thumaczeniu autora, chyba że zaznaczono inaczej.

3 G. Aloi, Speculative Taxidermy: Natural History, Animal Surfaces, and Art in the Anthropocene, Columbia University Press, New York 2018. 
dociekania o rzadko podejmowane zagadnienie taksydermii w kontekście sztuki, pytając o jej potencjał jako złożonej praktyki dyskursywnej, umożliwiającej przemyślenie i kontestowanie antropocentrycznej perspektywy. Śledząc przemianę zwierzęcej skóry $\mathrm{w}$ przedmiot, który jednak nadal pozostaje w pewnym sensie zwierzęciem, Aloi zwraca uwagę nie tylko na złożoność ontologiczną tego problemu, ale również na szerszą perspektywę ludzko-zwierzęcych historii.

Książka rozpoczyna się przewrotnie, od systematycznej, dekonstrukcyjnej analizy rzeźby Edgara Degasa Mała tancerka. Aloiego nie interesuje jednak sama jej forma i liczne reprodukcje odlewane z brązu. W swojej krytycznej analizie wraca do oryginału, który wyrzeźbiony (a raczej skonstruowany) został z różnych materiałów organicznych, takich jak wosk, drewno, liny i, co najważniejsze (i najciekawsze), prawdziwe ludzkie włosy. Zastosowanie „składników ciała” wywoływało w XIX wieku liczne kontrowersje i zostało odebrane jako nieomal skandal, co jest dla autora o tyle interesujące, że koresponduje z kompletną ambiwalencją wobec podobnego wykorzystywania w tym samym czasie (i na masową skalę) zwierzęcych skór. W tym kontekście Aloi kwestionuje fundamenty klasycznego, utopijnego realizmu zachodniej sztuki - dystansującego widza od rzeczywistego obiektu, który przekształca się w czystą ,formę symboliczną". Ludzkie ciało, wyrzeźbione w marmurze lub namalowane na płótnie, nie jest już namacalnym ciałem, staje się idea. Rzeczywista materialność ludzkich i zwierzęcych ciał, przedstawianych w tym paradygmacie sztuki, zostaje zakryta przez warstwę alegoryczną, która wprowadza bezpieczny (dla odbiorcy) dystans. Siła rzeźby Degasa leży w jej niekonwencjonalnym i szokującym realizmie, który zmienia układ odniesienia między widzem a obiektem - skracając dystans, zbliża go do rzeczywistego ciała. W ten sposób Aloi pokazuje zdolność utrwalonych ciał do łączenia tego, co jest symbolicznie przedstawiane w przestrzeni galerii i muzeów, z tym, co niewidzialne lub ignorowane na zewnątrz.

Autor celowo przeciwstawia się utrwalonemu przez muzea historii naturalnej i kolekcjonerów „romantycznemu", sentymentalnemu wizerunkowi zwierząt przedstawianych $\mathrm{w}$ postaci obiektów taksydermicznych. Aloi zwraca uwagę na częste w popularnej świadomości postrzeganie taksydermii jako „egzotycznej, interesującej czy zabawnej", co poniekąd ją bagatelizuje. Odwołuje się także do koncepcji tzw. „spartaczonej taksydermii" (botched taxidermy) Steve'a Bakera (Postmodern Animal, $2000^{4}$ ), ukazując taksydermię jako ,niezręczny produkt”, „dziwne stworzenie” - tyleż intrygujące, co odpychające. Kluczem do zrozumienia proponowanej koncepcji „spekulatywnej taksydermii” jest dostrzeżenie szczególnych właściwości spreparowanych zwierzęcych skór, ujmowanych przez Aloiego w kategorii tzw. „indeksowości”"s (s. 23-24),

4 S. Baker, Postmodern Animal, Reaktion Books, New York 2000.

5 Aloi pisze także o „właściwości indeksowej” i ,,indeksowości”, pojęcia te odnosi do koncepcji Charlesa S. Peirce'a, który ,indeksowość rozumie jako: właściwość znaku fizycznie połączonego $\mathrm{z}$ desygnowanym obiektem w relacji, która jest nieunikniona i konieczna". 
skupiającej w sobie skomplikowane sieci relacji między zwierzętami, ludźmi, naturą i sferą praktyk dyskursywnych ${ }^{6}$. W takim ujęciu widoczne jest wyraźne odejście od interpretacji na poziomie czysto estetycznym i aksjologicznym dekonstrukcja podmiotu kartezjańskiego i prymatu języka (fundamentalnych dla klasycznej sztuki) na rzecz zwrotu ku wzajemnym powiązaniom i interakcjom, materialności i indeksowości. Dotyczy to dyskursów i praktyk definiujących tzw. „zespoły” (takiego pojęcia używa autor, w latourowskim sensie chodzi o sieci) uwikłań politycznych, geograficznych $\mathrm{i}$ historycznych.

Dzięki wprowadzeniu podejścia spekulatywnego jako ramy teoretycznej możliwe jest zoperacjonalizowanie obiektów taksydermicznych w postaci tzw. ,aktywnych interfejsów” (tak nazywa je Aloi), za pomocą których można krytycznie badać proces konstruowania ludzko-zwierzęcych relacji. Pojęcie ,aktywności" odnosi się tutaj do zdolności otwierania pól spekulacji w sztuce - innymi słowy - zadawania ,spekulatywnych pytań”. W kontekście tych pytań taksydermia może być postrzegana jako

Cytat za: G. Aloi, Speculative Taxidermy ..., op. cit., s. 23. Zob. u Peirce'a: „This is a real thing or fact which is a sign of its object by virtue of being connected with it as a matter of fact and by also forcibly intruding upon the mind, quite regardless of its being interpreted as a sign", Ch.S. Peirce, Collected Papers of Charles S. Peirce, vol. 4, Belknap Press of Harvard University Press, Cambridge, MA 1960, s. 359.

6 To ,splotowe" rozumienie indeksowości wywodzi się z koncepcji systemu referencyjnego znaków i symboli Morgana Marcylieny. M.H. Marcyliena, Speech Communities, Cambridge University Press, Cambridge 2014, s. 15. rezultat złożonych negocjacji między dyscyplinami, porządkami i dyskursami. „Spekulatywność” ujawnia się w zdolności do uaktywniania potencjału krytycznego, który jest inherentnie wpisany w taksydermię i często znajduje swój wyraz w sztuce. W tym sensie ,spekulatywna taksydermia" jest dla Aloiego przemyślanym narzędziem badawczym, które umożliwia przeniknięcie przez nieistotną warstwę estetyczną obiektów i wniknięcie w głąb warstwy sieciowej - ,uaktywnienie jej jako interfejsu" i dostrzeżenie szeregu kontekstów postkolonialnych, ekonomicznych, ekologicznych i artystycznych, których splot wynika z zawiłej historii i „dziwnej”, „transformacyjnej” materialności taksydermii. Czyniąc to, autor rzuca wyzwanie przyjętym powszechnie historycznym modelom relacji ludzko-zwierzęcych, ukazując losy ludzi i zwierząt jako wzajemnie uwikłane i współzależne, nie zaś oparte na uproszczonym podziale na dominujących i dominowanych.

Książka podzielona jest na siedem rozdziałów, poprzedzonych prologiem i wstępem oraz skonkludowanych zakończeniem i apendyksem, który zawiera napisany przez Marka Diona i Roberta Marbury'ego manifest dla artystów zajmujących się taksydermią. W pierwszej części książki (szczególnie w pierwszym i drugim rozdziale) Aloi poświęca wiele miejsca zagadnieniom historycznym. Jest podejrzliwy w stosunku do dominujących metanarracji, które utrwalają pogląd o naukowym rodowodzie taksydermii i jej roli w produkowaniu wiedzy o naturze. Podejście to ma swoje korzenie jeszcze w XIX wieku, kiedy uczeni (w tym sami przyrodnicy) dążyli 
do popularyzacji taksydermii jako szlachetnego przedsięwzięcia naukowego. Zgodnie $\mathrm{z}$ takim, linearnym, rozumieniem historii taksydermia narodziła się przypadkowo jako rzemiosło ,wypychania skór zwierzęcych". Następnie ewoluowała, stając się naukowym narzędziem i obiektem artystycznym, osiagając szczyty doskonałości we współczesnych, hiperrealistycznych dioramach historii naturalnej. W takim ujęciu dominującym czynnikiem kształtującym taksydermię były powolne i sukcesywne postępy w technikach balsamowania, wypychania i montażu, które dziś możemy podziwiać w niemal doskonałych technicznie wytworach współczesnej taksydermii muzealnej. Przyglądając się tak skonstruowanej narracji historycznej, Aloi (jak sam pisze) podejrzewał, że kryje ona wiele ukrytych i skomplikowanych warstw, pominiętych przez dominujący dyskurs. Podejmując kwestię tradycyjnej historiografii i zagłębiając się w źródła taksydermii jako splotów dyskursów, praktyk i władzy, które posiadają różnorodne kulturowe następstwa, Aloi wykorzystuje przede wszystkim koncepcję archeologii wiedzy zaczerpniętą z prac Michela Foucaulta. Dla Aloiego najciekawsze jest proponowane przez Foucaulta odejście od linearnego, narracyjnego analizowania procesów historycznych, łączących pojedyncze wydarzenia i prowadzących do konstrukcji określonych opisów, na rzecz podejścia traktującego historię jako powolną sedymentację i przenikanie się pozornie niezwiązanych, równoległych dyskursów?

M. Foucault, Two Lectures, w: idem, Power/ Knowledge: Selected Interviews and Other
Proponowane przez francuskiego filozofa archeologiczne i genealogiczne metody analizy dyskursywnej zostały zastosowane do identyfikowania i ,mapowania" warunków, które umożliwiają praktykom i dyskursom tworzenie się i przenikanie. Ta perspektywa umożliwia konceptualizację taksydermii jako swoistej „klasy” przedmiotów będących materialnymi manifestacjami historycznych relacji człowiek - zwierzę, kształtowanych jednocześnie przez dyskursy władzy i wiedzy (s. 57). Metodologia oparta na ,archeologii wiedzy” i geneaologii proponowanej przez Foucaulta najwyraźniej uwidacznia się w podejmowanej przez Aloiego metodycznej dekonstrukcji i analizie tego, co nazywa „dziwną pętlą" (weird loop). Termin ten określa historyczną ciągłość zachodzących na wielką skalę praktyk montażu i demontażu ciał zwierząt, zarówno w kulturze i sztuce (fotografii, filmie, sztukach audiowizualnych i performatywnych), jak i w przemysłowej produkcji mięsa i w przetwarzaniu zwierzęcych ciał. Aloi odnosi się tutaj do ciekawych analiz Nicole Shukin z jej pracy Animal Capital: Rendering Life in Biopolitical Times, w której opisuje ona zawikłanie relacji ludzko zwierzęcych, które egzemplifikuje proces równoległego rozwoju rolnictwa przemysłowego, linii montażowych samochodów (wyznaczający początek ery masowej produkcji) i konstruowania reprezentacji zwierząt $w$ kulturze audiowizualnej ${ }^{8}$.

Writings, 1972-1977, ed. C. Gordon, Harvester Press, Brighton 1980, s. 78-108.

8 N. Shukin, Animal Capital: Rendering Life in Biopolitical Times, University of Minnesota Press, Minneapolis 2009. 
Autor odwołuje się także do pojęcia „życia społecznego rzeczy” Arjuna Appaduraia, które przenosi punkt ciężkości w rozważaniach nad rzeczami z pytań o ich ontologiczny status na pytania o ich funkcję ${ }^{9}$ umożliwiając w ten sposób dostrzeżenie unikatowego sprawstwa przedmiotów taksydermicznych w działaniu. W tym kontekście „taksydermia spekulatywna" odnosi się przede wszystkim do dzieł sztuki, w których skóra zwierzęca (lub jej reprezentacja) poddawana jest praktykom wizualnym oraz wystawienniczym, szczególnie jeśli chodzi o eksponowanie i konstruowanie obrazów natury w muzeach. Zwierzęce skóry poddane preparacji charakteryzuje, zdaniem autora, swoistego rodzaju "dynamika władzy i wiedzy" (s. 91), leżąca u podstaw praktyk estetycznych, których celem i skutkiem jest dokonanie wspomnianego ontologicznego przejścia (przemiany) zwierzęcia w przedmiot artystyczny/dzieło/eksponat. Ukazując taksydermię jako ważny sposób konceptualizacji zwierzęcia we współczesnej sztuce, autor posługuje się pojęciem ,medium reprezentacji” (medium of representation). Termin ten umożliwia mu wskazanie na jej znacznie większy (niż można by przypuszczać na podstawie analiz krytyków sztuki), ,ukryty" potencjał reprezentatywny (s. 23).

Rozważania prowadzone przez Aloiego osadzone są w dwóch głównych kontekstach: antropocenu i nowego materializmu. Punktem wyjścia jest dla niego perspektywa skomplikowanej współczesności, którą ukazuje jako rzeczywistość

9 The Social Life of Things: Commodities in Cultural Perspective, ed. A. Appadurai, Cambridge University Press, Cambridge 1988. kryzysu dominujących kapitalistycznych modeli produkcji, konsumpcji i podporządkowania - dotychczas determinujących relacje ludzi i zwierząt oraz szerzej - ludzi i natury. Znaczenie złożonej materialności taksydermii nie leży wyłącznie w jej potencjale symbolicznym, który często jedynie utrwala antropocentryczną interpretację, ale raczej w jej szczególnej właściwości, zidentyfikowanej przez Aloiego jako tzw. „rejestr biopolityczny” (s. 39). Pojęcie to nawiązuje do współczesnej ekonomii i produkcji masowej, autor odnosi je do problemu reżimów wyzysku produkcji przemysłowej, która łączy człowieka i zwierzę. To właśnie ten „biopolityczny rejestr” taksydermii ujawnia jej związki z zawartym w tytule antropocenem. Pomimo kontrowersji, jakie termin ten budzi we współczesnej humanistyce i niektórych naukach przyrodniczych (których autor jest świadom), służy on ogniskowaniu wpływu działalności człowieka na sieci wzajemnych powiązań, które charakteryzują biosferę w erze zmian klimatu. Antropocen jako postulowana nowa epoka geologiczna w dziejach ziemi, charakteryzująca się wszechobecnym i nieprzewidywalnym wpływem działalności człowieka na planetę. Ów wpływ jest bezpośrednio powiązany z nadmierną konsumpcją i eksploatacja, opierającymi się na głębokim poczuciu niepowiązania z naturą (wpisanym poniekąd w obowiązujący model kapitalizmu). $\mathrm{Z}$ teoretycznego punktu widzenia jest to wielkie wyzwanie wymagające opracowania nowych podejść i metodologii. Aloi odpowiada na ten problem, odnosząc się głównie do koncepcji „ciemnej 
ekologii" Timothy'ego Mortona ${ }^{10}$. Teoria ta jest dla niego dominującym sposobem rozumienia i konceptualizowania kryzysów kulturowych, środowiskowych, ekonomicznych i politycznych wynikających z antropocenu. Zdaniem Mortona angażowanie się w myślenie ekologiczne wykraczające poza czysto retoryczny poziom wymaga zanurzenia się $\mathrm{w}$ nierozwiązywalnych dwuznacznościach, nakładających się pętlach i ich (nierzadko) „,iemnych" konsekwencjach. Przykładem „ciemnej ekologii” antropocenu są zależności między ludzkimi działaniami radykalnie zmieniającymi środowisko i ich nieprzewidywalnymi konsekwencjami. Faktem jest, że zwierzęta dostosowują się do tych zmian, ,reagują" na ludzkie działania. W tym kontekście ludzka sprawczość jawi się nie jako siła jednoznacznie negatywna, „niszcząca” naturę, lecz jako czynnik powodujący niemożliwe do przewidzenia (nieuwarunkowane ewolucyjnie) zmiany, wytwarzający swoistą „ciemną naturę" nowych zależności.

Dyskurs nowego materializmu, podobnie jak pojęcie antropocenu, otwiera przed autorem konkretny obszar badawczy. Aloi argumentuje, że pojawienie się wielu współczesnych dzieł sztuki angażujących taksydermię zbiega się $\mathrm{z}$ odnowionym krytycznym zainteresowaniem ,życiem” i biografią rzeczy. Nieantropocentryczna sprawczość jest tutaj kluczową koncepcją; świat fizyczny to przede wszystkim sieć relacji między wpływającymi na siebie aktorami

10 T. Morton, Dark Ecology: For a Logic of Future Coexistence, Columbia University Press, New York 2016. wszelkiego rodzaju, żyjącymi i nieożywionymi, w tym dziełami sztuki. Rodzi się pytanie, jak pracują artyści tworzący swoje dzieła w ramach różnych ,spekulatywnych" podejść. Aloi ujmuje ten problem w oryginalny sposób, przyglądając się temu, jak ich dzieła (szczególnie ich materialność) moga zmieniać układy odniesienia w celu generowania nowej dynamiki w sieci. Jak się okazuje, wielu współczesnych artystów uważa taksydermię za wyraźne oświadczenie polityczne. Zwierzęce skóry są przez nich używane w celu bezpośredniego dyskutowania, problematyzacji i kwestionowania relacji między ludźmi a zwierzętami w kontekście problemów politycznych i ideologicznych.

Dla rzemieślników-artystów (za jakich taksydermiści często się uważali) taksydermia była okazją do ukazywania zwierzęcia w formie symbolicznej - całkowicie wyidealizowanej, sztucznej. Te klasyczne reprezentacje oparte były na uprzedmiotowieniu i podporządkowaniu zwierząt, które wpisywały się zarówno w rozwijający się antropocentryzm nauk przyrodniczych (opartych na paradygmacie darwinowskiej teorii ewolucji), jak i w dominujące systemy gospodarcze. Aloi pisze o ,płaskości” i jednowymiarowości reprezentacji zwierząt $\mathrm{w}$ nauce i sztuce - szczególnie biorąc pod uwagę fundamentalną dla kultury tendencję do antropomorfizacji oraz leżące u podstaw klasycznej estetyki zrównanie pojęć „prawdy” i „piękna”. Ciekawe jest jego odwołanie do analiz Rona Broglio z pracy Surface Encounters: Thinking with Animals and Art, dotyczącej utrwalonego w zachodnim paradygmacie naukowym podejścia do życia „innego niż ludzkie” 
jako pozbawionego głębi, zdolności autorefleksyjnych i poznawczych - co prowadziło do „spłaszczenia” i ,powierzchowności" w opisie i stosunku do zwierząt (s. 177) ${ }^{11}$. Głównym przykładem wkroczenia artysty $\mathrm{w}$ skrajnie antropocentryczny porządek nauk przyrodniczych są „krytyczne gabinety osobliwości” Marka Diona, kwestionujące klasyczne panopticum historii naturalnej i podkreślające arbitralne, antropocentryczne sposoby porządkowania leżące $u$ jego podstaw. Założeniem dioram $\mathrm{w}$ muzeach historii naturalnej było konstruowanie scen nieskażonej przyrody, których żyjący w cywilizacji ludzie nie mogliby doświadczyć. W omawianej przez Aloiego instalacji Landfill z 1999 roku Dion odwraca pojęcie ,czystości” i łączy je z pojęciem „rozkładu”, przedstawiając inną scenę: utrwalone taksydermicznie mewy srebrzyste (Larus argentatus) siedzą na górze śmieci $\mathrm{w}$ otoczeniu przypominającym składowisko odpadów. Ta swoista „antydiorama" jest skonstruowana harmonijnie, z pietyzmem i zachowaniem realizmu charakterystycznego dla typowych muzealnych instalacji. Takie przedstawienie służy jako wizualna reprezentacja opisanej wyżej „ciemnej ekologii” - natury zmienionej, nieidealnej, przekształconej, a jednak nie martwej - ludzkie działanie (wytwarzanie odpadków) spotkało się ze zwierzęcą reakcją: mewa srebrzysta jest gatunkiem oportunistycznym (nierzadko synantropijnym), ludzkie odpady są dla niej okazją, nowym „ciemnym” środowiskiem. W instalacji

11 R. Broglio, Surface Encounters: Thinking with Animals and Art, University of Minnesota Press, Minneapolis 2011. tej uderzające jest przełamanie muzealnego decorum (opartego na klasycznym pojęciu piękna), którego często poszukują widzowie - to natura, której ludzie nie chcą oglądać, jak pisze Aloi: „dystopijny realizm końcowych etapów dezawuowania kapitalistycznego konsumeryzmu" (s. 108).

Warto zauważyć, że praca Aloiego zawiera wyraźny komponent narracyjny - kolejne rozdziały balansują pomiędzy szerszymi historyczno-kulturowymi refleksjami a bliższymi analizami konkretnych dzieł sztuki, które egzemplifikują poruszane problemy. Oprócz omawiania prac Marka Diona autor sięga do przykładów twórczości wielu artystów, między innymi: Marii Papadimitriou, Nandiphy Mntambo, Berlinde De Bruyckere, Roni Horn, Steve'a Bishopa, Cole'a Swansona oraz Bryndís Snæbjörnsdóttir, Petah Coyne, Claire Morgan, Nicholasa Galanina, Kate Clark, Maurizia Cattelana i Marka Wilsona. Wnikliwe analizy ich prac pokazuja, w jaki sposób, badając splecione historie zwierząt i ludzi, ujawniaja się sposoby, w jakie to, co nieludzkie, jest kluczowe dla tego, co ludzkie. Bardzo cenne w omawianej pracy jest także wyjście poza kontekst sztuki zachodniej i przyjrzenie się również pracom artystów z Chin, takich jak Cai Guo-Qiang, Sun Yuan i Peng Yu, których oryginalne, surrealistyczne podejście do obiektów taksydermicznych służy pogłębieniu politycznego wydźwięku ich prac. Dzięki temu sztuka staje się potężnym narzędziem kontestowania chińskiej współczesności, którą trudno jest poddać jednoznacznej krytycznej ocenie, co z kolei umożliwia obejście cenzury. W kolejnych krytycznych rozdziałach powraca 
kluczowe pytanie: po co dziś patrzeć na zwierzęta? (Po raz pierwszy zadane przez Johna Bergera w jego słynnym eseju ${ }^{12}$ ). Pytanie to zostaje przez Aloiego odniesione również do zwierząt utrwalonych i reprezentowanych $\mathrm{w}$ postaci obiektów taksydermicznych. Odpowiedź jest nieoczywista i kryje się w naszej skomplikowanej relacji z materialnością zwierzęcych ciał. Zarówno żywe zwierzęta, jak i te, których ciała zostały przetransformowane w przedmioty i relokowane w sferę użytkową, naukową lub artystyczną, nadal są istotną częścią, ,antropogenicznego łańcucha pośrednictwa, w którym uwidaczniają się ludzie, zwierzęta, obszary geograficzne, materialność, ekonomia i biologia" (s. 192). W sztuce taksydermia działa $\mathrm{w}$ pewnym sensie przeciwko niewidzialności zwierzęcej śmierci, czyniąc ją szokująco widzialną, namacalną i nadając jej treść, której pozbawione są skórzane obiekty użytkowe (meble, książki, bibeloty itp.; rezultaty wspomnianej już „dziwnej pętli”) czy choćby kość słoniowa. Idąc za Bergerem (i poniekąd za Foucaultem), fizyczne zniknięcie zwierząt i zanik bezpośrednich ludzko-zwierzęcych relacji, spowodowane industrializacją, doprowadziły do ich kompensacyjnego rozmnażania w kulturze wizualnej. Patrzenie na taksydermię, szczególnie tę „spartaczoną,, zmieniona przez czas, zużyta, skłania widza do cięższej pracy nad dekonstrukcją jej oryginalnego znaczenia i kontekstu. Uniemożliwia ,oczarowanie", które leżało u podstaw wyidealizowanej reprezentacji klasycznych dioram

12 J. Berger, Why Look at Animals?, w: idem, About Looking, Vintage Books, New York 1992, s. 3-28.
- postrzeganie ciał zwierząt jako romantycznych i nostalgicznych z bezpiecznego dla widza dystansu. Taksydermia, której materialność jest dla widza szokująca, odpychająca, zmusza do zastosowania refleksji spekulatywnej i zadania pytań o jej indeksowość - paradoksalnie zbliża do zwierzęcia, które przekształcone w obiekt taksydermiczny, wraca do widza nie jako „dzieło sztuki”, ale martwe ciało żywej istoty, prowokując pytania o jego ,życie i biografię” oraz sieć relacji ludzko-zwierzęcych, która do tego doprowadziła.

Aloi poświęca również cały rozdział analizie skomplikowanych relacji między taksydermią i fotografią, a także prac współczesnych fotografów, takich jak Roni Horn, Richard Ross, Oleg Kulik, Karen Knorr i Hiroshi Sugimoto, którzy ujmując zwierzęce skóry w obiektywie aparatu, podejmują w swoich pracach krytyczne analizy dychotomii życia i śmierci, realności i iluzji. Aloi ponownie wraca tu do pytania: po co patrzeć na zwierzęta? Tym razem jednak przekształca je w pytanie: po co fotografować zwierzęta? Jego zdaniem fotografia uwolniła reprezentacje natury od obciążeń procesu twórczego (intelektualnego przetworzenia obrazu przez artystę), które dominowały w sztuce, tym samym poszerzając zakres samej reprezentacji. Szczególną właściwością zdjęć jest ich zdolność do ,zatrzymywania czasu”, która przyczynia się do narodzin nowego realizmu, przekraczającego ograniczenia rzeźby i malarstwa. Ma to kolosalne znaczenie dla nauki, która poszukuje jak najdokładniejszych i, ,prawdziwych” obrazów. Zgodnie z wyjaśnieniami Bergera fizyczna marginalizacja zwierząt, 
która charakteryzowała drogę ku nowoczesności, skutkowała wytworzeniem ich bardziej odpornej, kulturowej obecności, opartej na fundamencie obrazu fotograficznego ${ }^{13}$. Dla Aloiego ważne jest jednak dostrzeżenie, że fotografia nie odróżnia zwierzęcia żywego od martwego. W tym sensie fotografowanie „żywej przyrody” i obiektów taksydermicznych ma ten sam potencjał reprezentatywny. Aloi pokazuje taksydermię jako zawieszoną między fotografią a rzeźbą, z którymi dzieli podobne właściwości i podobną, ,indeksowość". Dzięki swojej zdolności do utrwalania obrazu z pełną dokładnością fotografia stała się także kluczowym elementem odtwarzania natury w hiperrealistycznych dioramach. Jednocześnie dla wielu artystów przedstawia medium ,podwójnego zdystansowania" od żywego zwierzęcia, a zarazem od jego utrwalonej skóry. Jest to narzędzie przewrotnych gier z odbiorcami obrazów, w których artyści zmuszają do kwestionowania intuicyjnej percepcji tego, co „żywe", i tego, co „martwe”, a zatem wszystkich kulturowo konstruowanych przedstawień natury, do których tak przywykli.

Najsłabszym punktem tej książki sa pytania o etyczne aspekty tworzenia i używania taksydermii oraz etyczne implikacje sztuki, która ją angażuje. W trzech ostatnich rozdziałach Aloi zawarł szereg dość pobieżnych i rozproszonych uwag na ten temat. Wydaje się jednak, że obszar ten nie jest dla niego ani interesujący (sam w sobie), ani tym bardziej kluczowy z punktu widzenia „spekulatywnej” metody. Mimo że autor dostrzega etyczny komentarz wpisany

13 Ibidem. $\mathrm{w}$ wiele $\mathrm{z}$ analizowanych prac, a nawet stara się go wyodrębnić (szczególnie w pracach Nandiphy Mntambo, Berlinde De Bruyckere i Steve'a Bishopa), to jednak nie udaje mu się rozwinąc spójnego ekokrytycznego komentarza, jakiego w tej sytuacji można by się spodziewać. Najciekawszy pod tym względem jest apendyks zatytułowany: Some Notes Toward a Manifesto for Artists Working with and about Taxidermy Animals, opracowany we współpracy z Markiem Dionem i Robertem Marburym (tytuł sugeruje formułowanie swoistej strategii dla artystów pracujących z materiałami pochodzenia zwierzęcego). Trudno oprzeć się wrażeniu, że Aloi mógł lepiej wykorzystać potencjał do dyskusji nad etycznymi implikacjami związków między taksydermią, kapitalizmem i antropocenem. Szczególnie biorąc pod uwagę zdanie Diona i Marbury'ego, że potworną rzeczą dla artysty jest zmarnowanie śmierci. Uderzające są skojarzenia, jakie ewokuje ta „rada dla artystów” z dyskutowaną po wielokroć w literaturze krytycznej obsesją efektywności i ekonomiką produkcji wpisaną w kapitalizm. Zwierzęta przetwarzane przemysłowo wykorzystywane są do cna, ponieważ nie są traktowane jak istoty, ale surowce produkcyjne. Tym bardziej interesujący wydaje się nacisk, jaki obaj artyści kładą w swoich „wskazówkach" na minimalizację odpadów i wykorzystywanie wszystkiego przy artystycznej pracy z taksydermią. Być może rozwinięcie tego rodzaju kwestii pomogłoby Aloiemu w lepszym i trwalszym powiązaniu spekulatywnych refleksji z zawartym $\mathrm{w}$ tytule antropocenem (który - jak już powiedziano - służy bardziej jako tło). Potencjał taksydermii jako 
środka ekokrytycznej i biopolitycznej refleksji nad technokapitalizmem, który definiuje sieci ludzko-zwierzęcych relacji $\mathrm{w}$ antropocenie, z pewnością zasługuje na dalsze, głębsze zbadanie.

Książka Giovanniego Aloiego zmieni sposób myślenia o ciałach zwierząt we współczesnej sztuce i życiu. Stanowi wyczerpujący i znakomicie opracowany teoretycznie wkład w studia ekokrytyczne i historię sztuki. Warto dodać, że polityczne implikacje pracy Aloiego są nie tylko podtekstowe; autor wyraźnie łączy swoje analizy ze współczesnymi debatami. Spekulatywna taksydermia nie ogranicza się zatem tylko do rozważań akademickich, jest to użyteczne i przemyślane narzędzie krytyczne, którego potencjał (podobnie jak potencjał samej sztuki) wykracza daleko poza galerie i muzea.

\section{Bibliografia}

Aloi G., Speculative Taxidermy: Natural History, Animal Surfaces, and Art in the Anthropocene, Columbia University Press, New York 2018.

Baker S., Postmodern Animal, Reaktion Books, New York 2000.

Berger J., Why Look at Animals?, w: idem, About Looking, Vintage Books, New York 1992, s. 3-28.
Broglio R., Surface Encounters: Thinking with Animals and Art, University of Minnesota Press, Minneapolis 2011.

Foucault M., Two Lectures, w: idem, Power/ Knowledge: Selected Interviews and Other Writings, 1972-1977, ed. C. Gordon, Harvester Press, Brighton 1980, s. $78-108$.

Haraway D., Teddy Bear Patriarchy: Taxidermy in the Garden of Eden, ,Social Text” 1984-1985, No. 11, s. 20-64.

MacKenzie J.M., The Empire of Nature: Hunting, Conservation, and British Imperialism, Manchester University Press, Manchester 1988.

Morton T., Dark Ecology: For a Logic of Future Coexistence, Columbia University Press, New York 2016.

Poliquin R., The Breathless Zoo: Taxidermy and the Cultures of Longing, Pennsylvania State University Press, University Park 2012.

Shukin N., Animal Capital: Rendering Life in Biopolitical Times, University of Minnesota Press, Minneapolis 2009.

Simpson M., Immaculate Trophies, „Essays on Canadian Writing" 1999, No. 68: Materializing Canada, s. 77-106.

The Social Life of Things: Commodities in Cultural Perspective, ed. A. Appadurai, Cambridge University Press, Cambridge 1988.

Wakeham P., Taxidermic Signs: Reconstructing Aboriginality, University of Minnesota Press, Minneapolis 2008. 